\title{
EFFECTS OF RATE-ALTERED LECTURES ON THE ACQUISITION OF TRUE KNOWLEDGE
}

\author{
Ralph Behnke and Michael Beatty
}
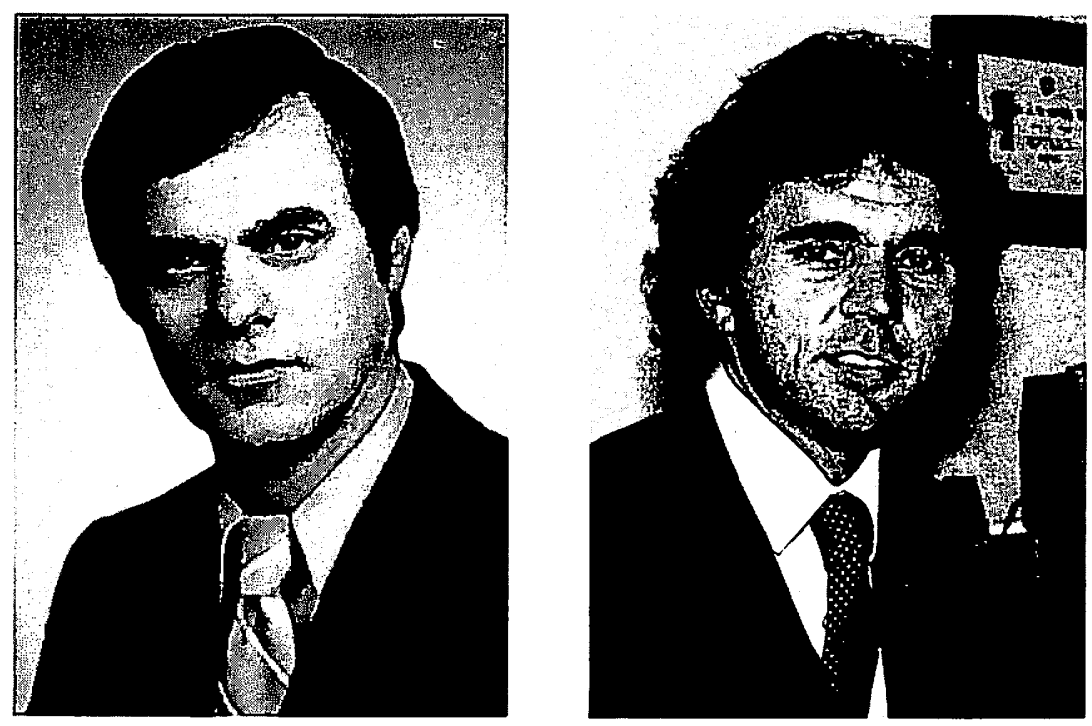

\begin{abstract}
The rapid proliferation of knowledge necessitates the development of more efficient instructional techniques. It may be possible to gain efficiency by accelerating the rate of tape recorded material. However, the increasing presentation rate increases work load. Information processing theories generally imply that superoptimal input loads severely impair the processing capabilities of communicatiton systems. One detrimental effect is reduction in accurate, absolute judgments produced by a communication system operating under overload conditions. Consequently, the quality of learning that occurs during accelerated speech is open for speculation. The present study operationalized load as rate of presentation and correct absolute judgments as true knowledge. Results indicate that increased rate severely attenuates true knowledge scores, a finding consistent with the conceptual framework upon which this study was based.
\end{abstract}


The rapid proliferation of knowledge and technology underscores the need for more efficient instructional techniques. Contemporary responses to this challenge may include the increased use of mediated techniques such as tape recorded lectures. Consequently, it is possible for students to audit instructional material while driving or relaxing at home. Clearly, as knowledge continues to expand, increased learning efficiency must be sought. At present, it is technologically feasible to accelerate tape recorded lectures to rate several times faster than the original recording rate. Thus, it would appear that considerable time could be saved by manipulating presentation rate in instruction.

Although most studies indicate that no significant loss of information results from listening to accelerated speech until word rates exceed 275 words per minute, or about twice normal speaking rate (Nelson, 1948; Fairbanks, Guttman \& Miron, 1957; Foulke, 1968), recent research has shown that increased presentation rates attenuate confidence in the material learned (Behnke \& Beatty, 1977; Beatty, Behnke \& Goodyear, 1979). One important question emerging from this research relevant to applying compressed speech techniques in medical instruction is: Do increased presentation rates reduce the number of concepts students learn with complete confidence? For example, there is considerable knowledge with which physicians only need to be generally familiar because in many situations, their uncertainty can be remedied through reference materials and consultation. However, there are other situations, such as emergencies, or surgery, which require immediate, and frequently irreversible decisions or absolute judgements. In such cases, physicians would be expected to rely upon approaches in which they have complete confidence or "true knowledge" (Goodyear \& Behnke, 1976). Consequently, the amount of "true knowledge" available to a physician may limit his medical options, particularly under stressful conditions.

Some insight concerning the affect of increased presentation rate on true knowledge can be gleened from the work of information theorists. Although there is disagreement as to whether information can be received simultaneously through more than one mode (Broadbent, 1958, 42; Norman, 1968; Garner, 1962, 116; Deutsch \& Deutsch, 1963), it is generally accepted that exceeding the maximum load capacity of a particular channel leads to dysfunctional information processing. Since memory trace and short term memory are essential to information acquisition in any mode (Miller, 1956; Broadbent, 216; Travers, 1970, 144), higher than optimal loads result in insufficient time to decode and sort incoming signals (Shroder, Driver \& Streufurth, 1967, 29-42). Consequently, the retrieval capabilities of communication systems functioning under superoptimal load conditions are severly impaired. A prime example of overloading the capacity of a system occurs when the amount of information transmitted, per-unit-time, is increased (Shroder, Driver \& Streufurth, 29-42).

Theoretically, exceeding load capacity will impact most heavily upon decision-making since this overload limits the ability to make absolute judgments (Pollack, 1952; Garner, 1953; Pollack \& Fricks, 1954; Miller, 
1956; Hsia, 1971). Consequently, the usefulness of information acquired under such conditions is attenuated. Applied to listening comprehension, an absolute judgement is manifest by complete certainty regarding the accuracy of the acquired information. Complete confidence in the correctness of the chosen alternative on a multiple-choice test, for example, represents an absolute judgment. Although traditional scoring procedures for multiple-choice tests do not provide information about the subjects' confidence in the chosen response (Goodyear \& Behnke, 1976; Behnke \& Beatty, 1977), a technique called confidence testing makes it possible to identify absolute judgments by providing information concerning subjects' confidence in their responses to test items. The accuracy of such judgment depends on whether or not the subjects' choice is the keyed response. Goodyear and Behnke (p. 61) label these correct, absolute judgments as "true knowledge."

The preceding discussion suggests that load increases, in the form of increased presentation rate, will produce corresponding decreases in accurate, absolute judgments (true knowledge). Therefore, the purpose of this study was to determine the effect of increased presentation rate on the acquisition of true knowledge.

\section{Stimulus Material}

\section{METHOD}

To insure that subjects would have no prior knowledge of the stimulus material, five taped versions of a lecture on the obscure topic of computer music were used in this study. The original $130 \mathrm{wpm}$ tape was recorded by a male speaker. A Vari-Speech I recorder with pitch normalizer was used to produce speeded versions of the stimulus material at $130 \mathrm{wpm}, 170 \mathrm{wpm}, 210 \mathrm{wpm}, 250 \mathrm{wpm}$, and $290 \mathrm{wpm}$. The range of acceleration selected for the stimulus material included rates typically considered the bounds of normal and accelerated speech. All five stimulus tapes were subjected to the Articulation Test for Intelligibility. The results of this test indicated that all five versions were highly intelligible $(100 \%$ to $96 \%$ ).

In order to secure information regarding the difficulty of the stimulus material, a transcript of the original tape was prepared and subjected to the Flesch Readability Index and the Dale-Chall Difficulty Index, a Grade Level Equivalency test and a comparison of sentence structures. The results indicated that the material was fairly difficult (Flesch $=49.55$; Dale-Shall $=8.91 ;$ GLE $=13.57$; and Sentence Similarity $=0.0 \%$ ).

\section{Dependent Variable}

A twenty question objectively-scored test over the subject matter presented on the tapes was used to measure information gain. The validity and reliability of this test was established in two earlier studies (Behnke \& Beatty, 19777; Beatty, Behnke \& Goodyear, 1979). The test featured a confidence-weighted format in which subjects divided the value of 1.00 among four choices according to their degree of confidence 
in the correctness of each choice. True knowledge scores were calculated by summing the keyed choices which had been assigned the probability of 1.00 (Behnke \& Beatty, 1977).

\section{Procedure}

The 200 Ss were randomly divided into five experimental conditions. Each group was exposed to only one stimulus tape. In all treatments, Ss were informed that they were about to hear a tape on the subject of computer music. Furthermore, they were informed that a comprehension test would follow the presentation. The tape was played following the instructions and the comprehension test was administered at the conclusion of the tape. Ss were advised of Rippey's instructions regarding confidence testing:

Your paper will be scored in such a way that you will get a higher score by estimating your degree of confidence and reporting it accurately. Guessing in any form will lower your score. If you are uninformed about the question and have no preference for a suggested answer, you will obtain your highest score by honestly distributing your confidence across all the options . . . (1970, 65).

\section{RESULTS AND DISCUSSION}

Means and standard deviations for the five listening groups are reported in Table 1. A simple linear regression indicated that 18.00 per cent of the variance between predicted and observed true knowledge scores can be attributed to the rate of presentation $(F=42.11$, df $=1 / 198$, $R=-.42 ; p$.01). A quadratic equation was used to test for significant deviation from linearity (Neter \& Wasserman, 1974, 273-277). This analysis contributed a nonsignificant addition to the variance attributable to the regression.

The results of the present study indicate that increased presentation rates are accompanied by corresponding decreases in true knowledge. This finding is consistent with theoretical expectations based on assumptions about information overload. Moreover, the linear relationship found between presentation rate and true knowledge greatly simplifies both theoretical and practical applications of this research. 
At the conceptual level, these findings support the proposition that increased information load reduces ability to make correct, absolute judgments. It appears that true knowledge scores provide a satisfactory operationalization of absolute judgment for cognitive tasks. Although the results of manipulating presentation rate did conform to theoretical expectations, other variables such as redundance and difficulty level should be investigated to determine their effects on the acquisition of true knowledge.

From a practical perspective, the findings of this study indicate that there is a tradeoff between the increased time-efficiency produced by compressed speech learning and the corresponding erosion of true knowledge scores. Although the information losses produced by increased presentation rates may be generally acceptable, they appear to be less advantageous when maximizing true knowledge is the goal of instruction.

Ralph R. Behnke

Michael J. Beatty

Dept. of Speech Communication

Texas Christian University

Fort Worth, TX 76129

(817) $921-7610$

\section{REFERENCES}

BEATTY, M. J., BEHNKE, R. R., \& GOODYEAR, F. H. Effects of speeded speech presentations on confidence-weighted and traditional comprehension scores. Communication Monographs, 1979, 46, 147-151.

BEHNKE, R. R., \& BEATTY, M. J. Effects of time-compressed speech on confidence-weighted comprehension scores. Southern Speech Communication Journal, 1977, 42, 309-317.

BROADBENT, D. E. Perception and communication. New York: Pargamon Press, 1958.

DEUTSCH, J. A., \& DEUTSCH, D. Attention: Some theoretical considerations. Psychological Review, 1963, 70, 80-90.

FAIRBANKS, G. GUTTMAN, N. \& MIRON, M. S. Effects of time-compression upon the comprehension of connected speech. Journal of Speech and Hearing Research, 1957, 22, 10-19.

FOULKE, E. Listening comprehension as a function of word rate. Joumal of Communication, 1968, 18, 198-206.

GARNER, W. R. An information analysis of absolute judgment of loudness, Joumal of Experimental Psychology, 1953, 46, 373-380.

GARNER, W. R. Uncertainty and structure as psychological concepts. New York: John Wiley, 1962. 
GOODYEAR, F. H. \& BEHNKE, R. R. Improving instructional systems through confidence testing. Communication Education, 1976, 25, 60-67.

HSIA, H. J. The information processing capacity of modality and channel performance. AV COMMUNICATIONS REVIEW. 1971, 19, 51-75.

MILLER, G. A. The magic number seven, plus or minus two: some limits on our capacity for processing information. Psychological Review, 1956, 63, 81-96.

NETER, J., \& WASSERMAN, W. Applied linear statistical models. London: Richard D. Irwin, Inc., 1974.

NORMAN, D. A. Toward a theory of memory and attention. Psychological Review, 1968, 75, 522-536.

POLLACK, I. The information of elementary \& audio displays. Journal of Acoustical Society of America, 1952, 24, 745-750.

POLLACK, I. \& FRICKS, L Information of elementary multidimensional auditory displays. Joumal of Acoustical Society of America, 1954, 26, 155-158.

RIPPEY, R. M. A comparison of five different scoring functions for confidence tests. Joumal of Educational Measurement, 1970, 7, 165-170.

SCHRODER, H. M., DRIVER, M. J., \& STREUFFRT, S. Human information processing. New York: Holt, Rhinehart \& Winston, Inc., 1967.

TRAVERS, R. M. W. Man's information system. Scranton: Chandler, 1970.

\section{TABLE I}

MEANS AND STANDARD DEVIATIONS

FOR TRUE KNOWI.EDGE

$\begin{array}{cccccc}\text { Rate (wpm) } & 130 & 170 & 210 & 250 & 290 \\ \text { X } & 4.61 & 4.30 & 3.49 & 2.17 & 2.05 \\ \text { SD } & 2.52 & 2.50 & 2.61 & 1.86 & 2.02\end{array}$

